Meulendijks, A., Batenburg, R., Wetering, R. van de. A classification framework for clinical information system implementation in hospitals. International Journal of Organisational Design and Engineering: 2012, 2(4), 402-419

\begin{tabular}{|l|l|}
\hline $\begin{array}{l}\text { Postprint } \\
\text { Version }\end{array}$ & 1.0 \\
\hline Journal website & http://www.inderscience.com/info/inarticle. php?artid=51443 \\
\hline Pubmed link & \\
\hline DOI & $10.1504 /$ IJODE.2012.051443 \\
\hline
\end{tabular}

This is a NIVEL certified Post Print, more info at http://www.nivel.eu

\title{
A classification framework for clinical information system implementation in hospitals
}

\author{
Arjan Meulendijks*: Utrecht University, P.O. Box 80007, 3508 TA Utrecht, The Netherlands \\ E-mail: arjan@meulendyks.nl *Corresponding author \\ Ronald Batenburg: Utrecht University, P.O. Box 80007, 3508 TA Utrecht, The Netherlands \\ E-mail: r.s.batenburg@uu.nl and Netherlands Institute for Health Services Research, P.O. \\ Box 1568, 3500 BN Utrecht, The Netherlands E-mail: r.batenburg@nivel.nl \\ Rogier van de Wetering: Utrecht University, P.O. Box 80089, 3508 TB Utrecht, The \\ Netherlands E-mail: r.vandewetering@uu.nl and Deloitte Consulting, P.O. Box 3180, 3502 \\ GD Utrecht, The Netherlands E-mail: rvandewetering@deloitte.nl
}

\begin{abstract}
:
In the last decade, many information system (IS) implementations took place in the healthcare organisations. Mainstream reasons for this evolvement are the increase of quality and safety of care, and reducing costs.

As in many other sectors IS implementations in healthcare are complex, and confronted with many types of difficulties that significantly hinder achieving the objected benefits. So far, a number of systematic overviews and classifications of critical success factors (CSFs) have been available for IS implementation in healthcare, but a CSF framework specifically for clinical information systems (CISs) in hospitals does not exist. This paper provides such a framework, validates it, and translates it into a practical contribution for IT project managers in hospitals.

The framework is based on a systematic literature review that has been performed to extract relevant SCFs from recent academic publications. After a filtering process, 58 publications have been selected from which 248 success factors have been extracted. Building upon seven existing classifications, the classification framework for CSFs in CIS implementations was build. Expert interviews were conducted to validate the framework and the relative weights of eight CSF categories.
\end{abstract}


Meulendijks, A., Batenburg, R., Wetering, R. van de. A classification framework for clinical information system implementation in hospitals. International Journal of Organisational Design and Engineering: 2012, 2(4), 402-419

\section{Reference}

to this paper should be made as follows: Meulendijks, A., Batenburg, R. and van de Wetering, R. (2012) 'A classification framework for clinical information system implementation in hospitals’, Int. J. Organisational

Design and Engineering, Vol. 2, No. 4, pp.402-419.

\section{Biographical notes:}

Arjan Meulendijks is a Business Intelligence Consultant at a Dutch SME. His job entails combining and analysing data from various sources. This is a power tool to gain insight in and improve a company's performance. By adding up all the data, he provides management with a tool to determine what is happening in their company and enhance decision-making.

He holds an MSc in Business Informatics from Utrecht University, The Netherlands. His research on CIS implementations was based on the combination of his personal interest in both informatics within healthcare and the implementation of information systems in (large) organisations.

Ronald Batenburg obtained his Masters from Utrecht University and his PhD in 1991 at Groningen University. After his $\mathrm{PhD}$, he worked at the Universities of Utrecht, Tilburg and Nijmegen as an Assistant Professor of Organisation Science, Strategic Policy Making and HRM. Since 2000, he is an Associate Professor at the Department of Information and Computing Sciences, Utrecht University. As of 2009, he combines this with a position as Programme Coordinator at the Netherlands Institute for Health Services Research (NIVEL).

His research interests and publications are in the field of strategic IT alignment, health care organisations, innovation and health manpower planning. Rogier van de Wetering is a Managing Consultant and Researcher at Deloitte's Public Sector Practice and Utrecht University. He holds both a Master's degree from Utrecht University and a PhD in Information Sciences and Medical Informatics. He works with a diverse client base including academic health sciences centres, local governments, NGO's and universities. He is active in several fields focusing on working with business executives, leaders, managers, physicians, radiologists, and front line staff to assess their business maturity and operations, identify improvement opportunities to enhance current benefits, both in terms of service/care quality and efficiency, and support (IT) implementation.

\section{INTRODUCTION}

Over the last decade managers and policy makers in healthcare have increasingly become aware of the need to deploy and mature the use of information systems (ISs) in hospitals. Likewise the number of papers have increased with case-studies about IS implementations and IS projects in hospitals, and also in nursing homes and primary care.

At a glance, much of these literature presents the same type of motives and drivers for this increased interest and evolvement in IS/IT. For instance, Culler et al. (2011) mention as motives to improve patient safety within the healthcare facility by having a more clear administration on the patients' data, being able to track orders and enhancing communication among departments, and reducing costs of the provided care caused by a higher efficiency. Another paper by Gruber et al. (2009) state that clinical information systems (CIS) mediate technological possibilities in healthcare 
Meulendijks, A., Batenburg, R., Wetering, R. van de. A classification framework for clinical information system implementation in hospitals. International Journal of Organisational Design and Engineering: 2012, 2(4), 402-419

by improving efficiency and effectiveness of services. Øvretveit et al. (2007) state that implementing an IS in a healthcare environment creates great potential to improve safety and quality, possibilities to reduce costs, and new service innovations. Likewise, Bhattacherjee and Hikmet (2007) claim that the most important reasons to implement IS in the healthcare industry are to reduce medical error rates, to improve healthcare delivery quality and to lower healthcare costs. According to Stablein et al. (2003), hospitals in the USA have adopted the computerised physician order entry (CPOE) systems because of a more efficient and manageable method of creating orders for hospitalised patients. And even earlier studies, such as by the Health Canada (1999) are similar in the motives mentioned, to be able to improve information management, to have better access to health services, quality and safety of care, and to create insight in continuity of services and cost containment.

A recurrent statement in literature is that the healthcare industry lags behind other industries in effectively exploiting IT for reducing costs and improving quality of services (Øvretveit et al., 2007). Cho et al. (2008) state that investments in healthcare ISs rose rapidly in the last years but by resisting the given benefits of such systems, the healthcare industry undermines potential benefits of IS implementations. Cho et al.

(2008) relate implementation difficulties to several causes: knowledge and management, people and organisations, social communication patterns, organisational structure and culture, resistance to change, and divergent interests across stakeholder groups. Øvretveit et al. (2007) likewise notice state that IS/IT are difficult to implement since they are part of a larger health system that need to balance multiple purposes and connects different organisations. At the national level, they mention the slow progress of the national Electronic Medical Record (EMR) in the UK as an example. This EMR should be implemented in all National Health Service (NHS) hospitals by 2005, but in 2003 only 3\% met the target, and in 2006 the deadline was postponed (Øvretveit et al., 2007). Also at the level of healthcare organisations, a typical problem is when starting a new IS project all major stakeholders have to agree on it. Even though the board of directors, the CEO, and major user groups (i.e., physicians, nursing staff) understand what kinds of advantages are feasible, it still remains difficult to justify costs of investments on IT projects (Leidner et al., 2010). CIO's in hospitals have a difficult decision task whether to pursue IT innovation or not. A successful IS implementation can result in many advantages, whereas an unsuccessful project may result in a loss of credibility with top management and skepticism about future IT investments (Leidner et al., 2010).

van der Meijden et al. (2003) claim that in healthcare new innovations will be predominantly judged by the direct value they offer for the patient. Only IS with a demonstrable practical utility for patient care or diagnostic procedures will be relatively easily accepted.

The stakeholders that are expected to benefit from the adoption and use of new IS still have a strong resistance towards it. Paré et al. (2011) even report about boycotts of installed computer-based systems or strikes of physicians to oppose an implementation of a new EMR system. Freudenheim (2004) published an article about physicians at the Los Angeles' Cedars-Sinai Medical Center who rebelled against a newly installed CPOE system. Their complaint was that the systems 
Meulendijks, A., Batenburg, R., Wetering, R. van de. A classification framework for clinical information system implementation in hospitals. International Journal of Organisational Design and Engineering: 2012, 2(4), 402-419

distracted them too much from their medical duties. They forced the withdrawal of the system after it was already implemented in two-thirds of the 870-bed hospital. Gillespie (2002) reports that also nurses can be reluctant to use computers, as they fear to be distracted from patient care.

IS implementation projects can fail because of nursing resistance. Doctors and nurses as the stakeholders who experience the biggest changes, have to see the benefits of the new IS transformation. Because they are largely responsible for the success of a new IS, they should be involved in the process of implementation. As a potential solution, De Mul et al. (2004) claim that social, political, and organisational aspects should all be recognised to determine the success of IS implementations in healthcare. Because of the complex, fluid, and socio-cultural aspects of healthcare work, the implications for IS development and implementation call for a sociotechnical approach. The difficulty with implementing a new IS is not the technical installation, but the creation of new work practices supported by this new system (De Mul et al., 2004). In line with this, Berg (2001) stated that: “A well-functioning system exemplifies a match between the functionalities of the system and the needs and working patterns of the organization".

While all the (classes of) factors and mechanisms mentioned so far are important with regard to IS deployment in healthcare, a framework to overview of their interconnection and underlying structure is lacking (Gruber et al., 2009). This research aims to provide such a framework by focusing on CISs implementations in hospitals. The aim is to construct a framework that is based on literature and theory, and at the same time is applicable in practice. In the next section, we first present a systematic literature review on studies that address success factors on IS implementations in healthcare organisations.

Then we explain how the framework is constructed, and next how expert interviews were conducted to validate it. Both the literature base and expert experiences are finally combined to define a number of practical guidelines for project managers. The paper closes with a summary and conclusion.

\section{METHODS AND RESEARCH STEPS}

\subsection{The systematic literature review}

The systematic literature review performed as the first step of this study is aimed to extract success factors mentioned in recent scientific publications on CIS implementations. Five large databases have been searched: PubMed, Embase, Web of Science, CINAHL and EBSCO ASE. For each database a specific query was constructed.

The constructed queries consist of three parts: 1 The first part ensured that a component of IT would be included in the resulting publications by searching for 'information technology', 'information technologies', 'ICT' or 'information and communication technologies'.

2 The second part focused on the environment of a hospital by searching for the term 'hospital', 'clinic' or 'medical centre'.

3 The third part of the query focused on the subject of implementation by using 'implemen*'. This includes all words starting with 'implemen'.

By performing the search queries a list of titles was generated. All included titles, with a link to the corresponding abstracts, were saved in a list and structured in a database. By sorting this list, duplicates were detected and removed from the results 
Meulendijks, A., Batenburg, R., Wetering, R. van de. A classification framework for clinical information system implementation in hospitals. International Journal of Organisational Design and Engineering: 2012, 2(4), 402-419

of the corresponding database. This induces that no duplicates were removed from the results of the first database in the list, in this case the PubMed database. The resulting list was used to select publications based on title. By following the corresponding link the abstract was shown, which made it possible to select publications based on their abstract. For this selection the following criteria for inclusion were applied: 1 a qualitative-, quantitative- or mixed method methodology was used to collect original data 2 the publication concerns a situation in which at least a part of a CIS implementation is described 3 the described CIS implementation was performed in a hospital environment 4 the publication describes factors that contribute to the success of the implementation project 5 the described CIS implementation was performed in a hospital in a developed country or compasses a mature hospital in terms of IT infrastructure (this excludes projects described in third world countries) 6 the publication is reported in English.

After the filtering process (removing duplicates, selection based on title, selection based on abstract, selection based on content) the included publications were saved and studied to extract factors that were mentioned by the authors as being related or relevant to CIS implementation projects positively and/or negatively. The factors were retrieved and identified by personal interpretation of the authors, crosschecking selection and definition of factors on a random base. Before executing this part of the systematic literature review, a common frame for factor selection and extracting was defined by the authors. The two most important guidelines were 1 to only select factors that were related to the original empirical research reported in the publication 2 to literally copy the factors as worded by the authors, to eventually rename and/or categorise them in the next step.

This extraction process resulted in a long list of what can be labelled as critical success factors (CSFs) - although this term was not always mentioned or used as such in the publications.

\subsection{Constructing the framework}

Parallel with the systematic literature review, specific publications were retrieved that not reported results from original empirical research, but a meta-study, systematic literature review, or a scoping review. These publications are of special relevance for this research step, as in most cases they present classifications and frameworks themselves that can directly be used to construct the aimed CIS implementation framework. The studies that were used to construct our framework are: 1 Øvretveit et al. (2007) 2 van der Meijden et al. (2003) 3 Stablein et al. (2003) 4 Kouroubali (2003) 5 Keshavjee et al. (2006) 6 Marques et al (2011) 7 Callen et al. (2009).

To construct our framework we synthesised (or: mapped) the seven frameworks and classifications as developed by these authors, taking completeness, coherency and practical applicability into account. The next section presents the results.

\subsection{Expert interviews}

The third step of the study consisted of seven expert interviews that were conducted to validate our framework. Before starting the interview, this research project was briefly explained. The interviewees were asked whether they agreed on recording the interview, explaining that this was done for processing the received detailed information. The interviewees received the transcribed interview text for approval. It was promised that citations remain anonymous and confident. 
Meulendijks, A., Batenburg, R., Wetering, R. van de. A classification framework for clinical information system implementation in hospitals. International Journal of Organisational Design and Engineering: 2012, 2(4), 402-419

For this study, experts are selected that hold aggregated and specific knowledge and are 'networked and motivated persons. Following Meuser and Nagel (2005), an expert is a person who is responsible for the development, implementation, or control of solutions, strategies, or policies. Also, this person has privileged access to information about groups of persons, or decision processes. An expert is not always 'neutral' but plays an important role in the definition of problems. The experts that were selected to hold three types of knowledge: 1 Technical knowledge, specific knowledge in the field and details on operations to understand the environment of the case in detail, in order to explain what happened during the process of implementation.

2 Process knowledge, about the processes that are involved to understand the process of implementation in order to report different success factors.

3 Explanatory knowledge, to collect subjective interpretations of relevance, rules, and beliefs. This type of knowledge is important as the experts should be able to explain their beliefs on to what extent a factor influences the success of a IS implementation.

The interviews consisted of three parts, as shown in Figure 1. The first part focused on the expert's experience and the case, the second part discusses the success factor categories, and the third part seeks for the expert's guidelines on best practices.

\section{[FIGURE 1]}

The first part of the interview focused on the expert's experience in CIS implementations.

The second part discusses the framework and its CSFs. The third part queried the expert's

view on best practices in CIS implementations in hospitals. The results from this part of

the interview are not used for this paper.

\section{RESULTS}

\subsection{The systematic literature review}

After the stepped selection procedure as explained above, a set of 58 publications remained for extraction and analysis. The 58 references are presented in Appendix. Figure 2 summarises how the exclusion of papers evolved over the selection steps, starting with 1,431 publications of which the majority (over $60 \%$ ) was retrieved from PUBMED.

\section{[FIGURE 2]}

Of the 58 studies, $56 \%$ of the publications reported on CIS implementations in hospitals in the USA, 7\% hospitals in Australia, 7\% on hospitals in the UK. The other papers described hospitals in different European countries, India and Taiwan. This bias towards English speaking countries is a common result from the language selection applied, and the fact that scientific production in the field of ISs and health 
Meulendijks, A., Batenburg, R., Wetering, R. van de. A classification framework for clinical information system implementation in hospitals. International Journal of Organisational Design and Engineering: 2012, 2(4), 402-419

is led by US authors or authors that are employed by US universities or research institutes.

Analysing the years of the 58 publications, Figure 3 demonstrates that the number of papers on CIS implementation is increasing; most studies have been published over the last six years. Before 2005, the subject of IT success in hospitals was addressed only sparsely, although it should be accounted that the total number of publications has increased extremely during the last five to ten years as well. The SLR was performed at the beginning of 2011, which explains the low frequency score in that year. It remains an interesting question if the lower frequency in 2010 indicates a temporarily 'dip' in the publication stream about the subject of CIS implementations in hospitals, or marks 2009 as the year in which the scientific interest in this subjected has peaked.

\section{[FIGURE 3]}

All 58 publications were classified by the authors according to the type of (original) research that was presented in the paper. The majority of publications report on case studies of (single) hospitals, using interviews, observation or focus groups as methods.

Quantitative research (based on survey or secondary data and statistical analysis) is represented in $31 \%$ of the publications. This is an understandable result given the complexity of the subject which is probably best approached by more explorative, qualitative methods. Also, the lack of standard measurements to collect data about IT projects in hospitals probably explains why quantitative methods are less applied.

\subsection{The CSFs extracted and classified into a framework}

The 58 included publications were studied by the authors in order to extract all relevant factors mentioned in the paper, following the extraction procedure as explained in the previous section. This coding analysis resulted in 248 success factors extracted from the papers, according to the name or label that was used by the authors. Given that the notation (naming, wording) of the factors differed between publications, but in most cases factors refer to the same concept, the next step was to group the 248 factors for further analysis.

As explained before, seven specific publications were used to derive a new, applicable and informative categorisation of CSFs of CIS implementation in hospitals (i.e., Øvretveit et al., 2007; Stablein et al., 2003; Kouroubali, 2003; Keshavjee et al., 2006; Marques et al., 2011; Callen et al., 2009; van der Meijden et al., 2003).

The categorisations of these seven authors/papers were compared and then integrated by the authors. The requirement of the new classification was to provide a practical overview on the one hand, and to cover the variation of the selected literature on the other. The mapping and synthesising exercise resulted in eight different CSF categories that were defined as the base of the framework, labelled by the authors as: 1 system 2 user 3 project management 4 resources 5 organisation 6 workflow 7 IT infrastructure 8 evaluation.

\section{[FIGURE 4]}

On purpose, the names of the new categories were kept as short as possible while at the same time covering a relatively homogeneous class of success factors. Figure 4 
Meulendijks, A., Batenburg, R., Wetering, R. van de. A classification framework for clinical information system implementation in hospitals. International Journal of Organisational Design and Engineering: 2012, 2(4), 402-419

shows how the classification categories of the seven authors were mapped to the eight newly defined categories.

Next, we shortly describe the content of each category, summing mist of the relevant factors per category: 1 System: This category includes the success factors which have affinity with the system that will be implemented. Obviously, most success factors have a connection with the system that will be implemented, but this category focuses mainly on the features or properties of the system. Examples of success factors which will be assigned to this category are: 'usability', 'data accuracy', and 'reliability'. Success factors like 'perceived ease of use' will also be assigned to this category, as well as to the user category, because the user is the actual person who perceives the properties of the system.

2 User: The user category focuses on success factors that are connected with users. This connection includes a broad scope of factors. Examples are: 'the involvement of users during the phase of requirements gathering', 'the education or experience of users', but also 'user acceptance of the new system'.

3 Project management: This category explicitly stems from one of the selected publications including success factor categories. It includes an important range of success factors. Project management gives guidance to an implementation project. The project manager has an important role because this is the person who communicates with the stakeholders, e.g., the future users or the organisation. This category includes success factors like: 'management support', 'leadership', and 'staged implementation'.

4 Resources: This category has a limited scope but was mentioned by most of the seven papers as important. Success factors like: 'enough people' and 'flexible budgets' are included. Resources are unpretentious needs which are involved in any type of implementation project.

5 Organisation: This category might be interpreted as close to the 'system' and user' categories but finds itself on a different level. For the success of a project the organisation and its culture can be important. Examples of success factors assigned to this category are: 'change readiness', 'organisational structures', and 'communication'.

6 Workflow: This category has success factors assigned that are connected to ongoing processes in a hospital, the workflow. Examples of success factors are: 'frequency of use', 'changed documentation habits', and 'impact on patient care'. When a new IS project is implemented, many stakeholders in a hospital are affected in their daily activities. It is important that care processes do not change too much or that it is clear what the advantage is when processes change.

7 IT infrastructure: The success factors assigned to this category focus on the IT infrastructure of a hospital. Examples of success factors are: 'hardware', 'networks', and 'performance of the network'.

8 Evaluation: This category focuses on the actual evaluation of the IS implementation.

Because a project has no clearly defined start- and endpoint, it is an ongoing process, evaluation of phases can be important to achieve success. While the project management category is based on actively managing a project and its future, this category has success factors assigned that look back and evaluate. Examples of these success factors are: 'feedback', 'dialogue', and 'support'. 
Meulendijks, A., Batenburg, R., Wetering, R. van de. A classification framework for clinical information system implementation in hospitals. International Journal of Organisational Design and Engineering: 2012, 2(4), 402-419

All 248 success factors extracted from the 58 publications were allocated into our classification framework, i.e., over the eight categories. This was done by the authors in line with the first extraction process, and in interaction when necessary. This allocation process cumulated the confidence that the classification was extended enough to cover all factors, and at the same time sparse enough to be overviewed and structured. It turned out that most of the 248 factors were allocated to the category 'project management' (25\%), another substantial proportion to the categories 'user' (21\%), 'organisation' (20\%) and 'system' (14\%). Quite interestingly, only a few SCFs were allocated in the categories 'evaluation' and 'IT infrastructure' (3\% and $4 \%$ ) and the categories 'resources' and 'workflow' (6\% and 7\%).

\subsection{Expert validation of the CSF categories found from literature}

The main part of the interview focused on the success factors and categories found in the systematic literature review. The list eight categories and their explanation, as shown above, was presented and shortly explained to the experts. Three of the experts stated that the classification was very recognisable and suggested that it needed no adaptation. The other four experts also understood the framework, made some minor suggestions to adapt it, and were specifically interested in how the factors were extracted and allocated. Then it was explained to the experts that four categories covered most of the original CSFs as extracted from the 58 publications [e.g., 'project management' (25\%), 'user' (21\%), 'organisation' (20\%) and 'system' (14\%), see previous section]. The experts very well understood this result confirming that these four factors can be considered as a 'top 4'.

One expert stated that the factor 'IT infrastructure' is actually more 'important' than suggested by the result from the literature review and CSF allocation. With most expert it was discussed whether the frequency a CSF was mentioned in literature really reflects its importance.

\section{CONCLUSIONS AND DISCUSSION}

In this paper a classification framework for CIS implementations in hospitals is developed, described and validated. The basis for the framework is a specific SLR conduced in 2011. This SLR shows that empirical studies on IS/IT implementation in hospitals are merely US-based case studies published between 2006 and 2010. From 58 carefully selected publication, a total of 248 SCFs were extracted. Then, seven important publications in the field were compared with regard to their classifications of CSFs, resulted into a meta classification of eight categories for CIS implementations. All 248 success factors were subsequently allocated over these eight categories. It appears that most CSFs belong to four categories: project management, user aspects, system aspects, and organisation aspects. The classification framework and the allocation of the CSFs were confirmed by seven selected experts that were deeply and recently involved in the practice of CIS implementation in Dutch hospitals.

To the best of our knowledge, the classification framework for CIS implementations in hospitals developed in this paper, can be considered as one of the first (or few) in its field. Although it is derived and validated as carefully as possible, its real value needs to be further demonstrated and investigated. Further research can be performed on other types if IS/IT systems in hospitals, exploring if the same type of CSFs would result from an SLR and classification routine. Also the number of experts and CIS projects to validate the framework can obviously be increased. Finally, it would 
Meulendijks, A., Batenburg, R., Wetering, R. van de. A classification framework for clinical information system implementation in hospitals. International Journal of Organisational Design and Engineering: 2012, 2(4), 402-419

be useful to let other researchers replicate the classification and allocation exercise to aggregate the list of 248 CSFs into the eight categories.

During our SLR and study, we found the need for a common definition of what a CIS implementation actually is, and how its success can be defined and measured.

Further research can be performed to develop such specific definitions. Doing so it is important to take different types of hospitals and different stakeholders into account. Project manager might have a different vision on what success of a CIS implementation is; and so have users, board of directors, IT vendors, healthcare professionals and so on. This draws back on the extended and complex stakeholder environment every hospital is in nowadays, probably regardless its type and location. The classification framework for CIS implementations as developed in this paper might hence be also stakeholder sensitive (i.e., 'situational').

\section{REFERENCES}

Barakah, D.M. and Alwakeel, S.S. (2009) 'Impact of CPOE on physicians and dentists' work performance at King Saud Medical Complex Hospital: a case study', Proceedings of the World Congress on Engineering and Computer Science, Vol. 1, pp.20-22.

Berg, M. (2001) 'Implementing information systems in health care organizations: myths and challenges', International Journal of Medical Informatics, Vol. 64, Nos. 2-3, pp.143-156.

Bhattacherjee, A. and Hikmet, N. (2007) 'Physicians' resistance toward healthcare information technology: a theoretical model and empirical test', European Journal of Information Systems, Vol. 16, No. 6, pp.725-737.

Callen, J., Braithwaite, J. and Westbrook, J. (2009) 'The importance of medical and nursing sub-cultures in the implementation of clinical information systems', Methods of Information in

Medicine, Vol. 48, No. 2, pp.196-202.

Cho, S., Mathiassen, L. and Nilsson, A. (2008) 'Contextual dynamics during health information systems implementation: an event-based actor-network approach', European Journal of

Information Systems, Vol. 17, No. 6, pp.614-630.

Culler, S.D., Jose, J., Kohler, S. and Rask, K. (2011) 'Nurses perceptions and experiences with the implementation of a medication administration system', Computers Informatics Nursing, Vol. 29, No. 5, pp.280-288.

De Mul, M., Berg, M. and Hazelzet, J.A. (2004) 'Clinical information systems: CareSuite from Picis', Journal of Critical Care, Vol. 19, No. 4, pp.208-214.

Desai, A., Desai, P., Blum, M. and Bates, D. (2006) 'Leveraging change: educational opportunities in information technology implementation', Journal of Clinical Outcomes Management, Vol. 13, No. 7, 372p.

Freudenheim, M. (2004) 'Many hospitals resist computerized patient care', New York Times, $6 p$.

Gillespie, G. (2002) 'Often a tough sell to nursing staff', Health Data Manage, Vol. 10, No. 4, pp.56-60.

Gruber, D., Cummings, G.G., LeBlanc, L. and Smith, D.L. (2009) 'Factors influencing outcomes of clinical information systems implementation: a systematic review', Computers, Informatics,

Nursing: CIN, Vol. 27, No. 3, pp.151-163.

Health Canada (1999) Towards a Healthy Future: Second Report on the Health of Canadians,

Federal, Provincial and Territorial Advisory Committee on Population Health, Ottawa.

Keshavjee, K., Bosomworth, J., Copen, J., Lai, J., Kucukyazici, B., Lilani, R. and Holbrook, A.M.

(2006) 'Best practices in EMR implementation: a systematic review', AMIA 2006 Symposium Proceedings, $982 \mathrm{p}$.

Kouroubali, A. (2003) Implementation of Health Care Information Systems: Key Factors and the 
Meulendijks, A., Batenburg, R., Wetering, R. van de. A classification framework for clinical information system implementation in hospitals. International Journal of Organisational Design and Engineering: 2012, 2(4), 402-419

Dynamics of Change, June, pp.1-17, University of Cambridge, Cambridge.

Leidner, D.E., Preston, D. and Chen, D. (2010) 'An examination of the antecedents and consequences of organizational IT innovation in hospitals', The Journal of Strategic Information Systems, Vol. 19, No. 3, pp.154-170.

Marques, A., Oliveira, T., Dias, S.S. and Martins, M.F.O. (2011) 'Medical records system adoption in European hospitals', Electronic Journal of Information Systems Evaluation, Vol. 14, No. 1, pp.89-99.

Menachemi, N., Brooks, R.G., Schwalenstocker, E. and Simpson, L. (2008) 'Use of health information technology by children's hospitals in the United States', Pediatrics, Vol. 123, Suppl., pp.S80-S84.

Meuser, M. and Nagel, U. (2005) 'ExpertInneninterviews - vielfach erprobt, wenig bedacht', in Bogner, A., Littig, B. and Menz, W. (Eds.): Das Experteninterview. Theorie, Methode, Anwendung, 2nd ed., pp.71-93, Verlag für Sozialwissenschaften, Opladen.

Nanji, K.C., Cina, J., Patel, N., Churchill, W., Gandhi, T.K. and Poon, E.G. (2009) 'Overcoming barriers to the implementation of a pharmacy bar code scanning system for medication dispensing: a case study', Journal of the American Medical Informatics Association, JAMIA, Vol. 16, No. 5, pp.645-650.

Øvretveit, J., Scott, T., Rundall, T.G., Shortell, S.M. and Brommels, M. (2007) 'Improving quality through effective implementation of information technology in healthcare', International

Journal for Quality in Health Care: Journal of the International Society for Quality in Health Care/ISQua, Vol. 19, No. 5, pp.259-266.

Paré, G., Sicotte, C., Poba-Nzaou, P. and Balouzakis, G. (2011) 'Clinicians' perceptions of organizational readiness for change in the context of clinical information system projects: insights from two cross-sectional surveys', Implementation Science, IS, Vol. 6, No. 1, 15p.

Shield, R.R., Goldman, R.E., Anthony, D.A., Wang, N., Doyle, R.J. and Borkan, J. (2010) 'Gradual electronic health record implementation: new insights on physician and patient adaptation', Annals of Family Medicine, Vol. 8, No. 4, 316p.

Spetz, J. and Keane, D. (2009) 'Information technology implementation in a rural hospital: a cautionary tale', Journal of Healthcare Management/American College of Healthcare

Executives, Vol. 54, No. 5, 337p.

Stablein, D., Welebob, E., Johnson, E., Metzger, J., Burgess, R. and Classen, D.C. (2003) 'Understanding hospital readiness for computerized physician order entry', Joint Commission

Journal on Quality and Patient Safety, Vol. 29, No. 7, pp.336-344.

Tietze, M.F., Williams, J. and Galimbertti, M. (2009) 'Rural hospital information technology implementation for safety and quality improvement: lessons learned', Computers, Informatics,

Nursing: CIN, Vol. 27, No. 4, pp.206-214.

van der Meijden, M., Tange, H., Troost, J. and Hasman, A. (2003) 'Determinants of success of inpatient clinical information systems: a literature review', Journal of the American Medical

Informatics Association, Vol. 10, No. 3, 235p.

\section{[APPENDIX]}


Meulendijks, A., Batenburg, R., Wetering, R. van de. A classification framework for clinical information system implementation in hospitals. International Journal of Organisational Design and Engineering: 2012, 2(4), 402-419

TABLES AND APPENDIX

Figure 1 The interview protocol applied in the seven expert validation interviews

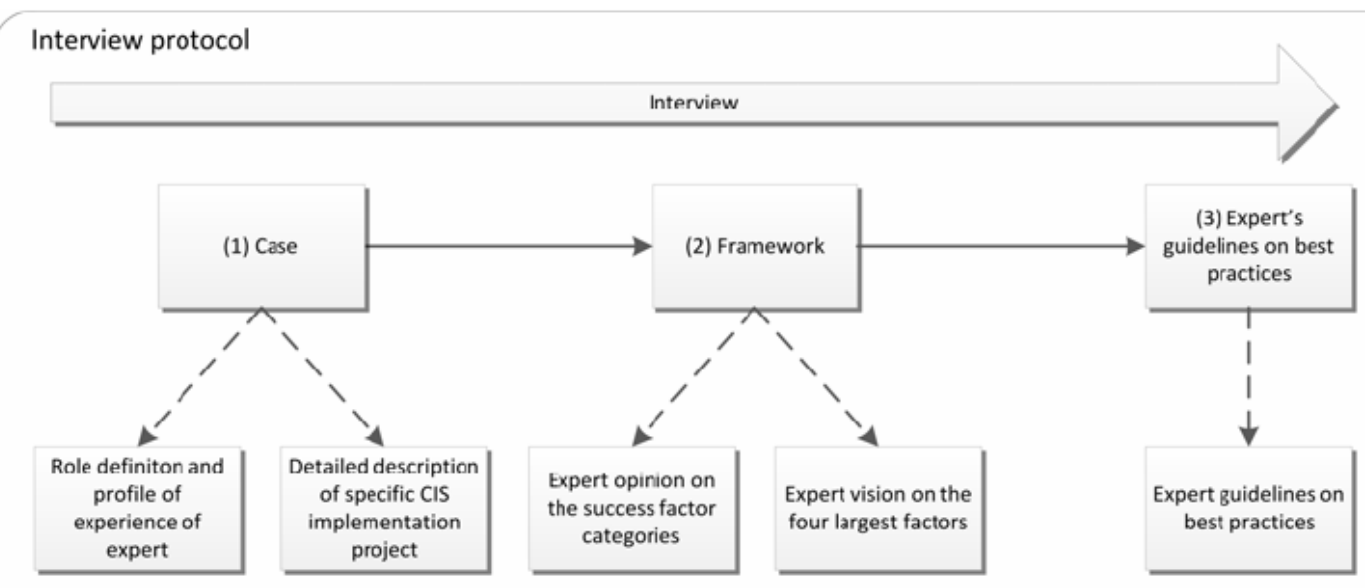


Meulendijks, A., Batenburg, R., Wetering, R. van de. A classification framework for clinical information system implementation in hospitals. International Journal of Organisational Design and Engineering: 2012, 2(4), 402-419

Figure 2 Results of the SLR

Systematic Literature Review: Filtering process

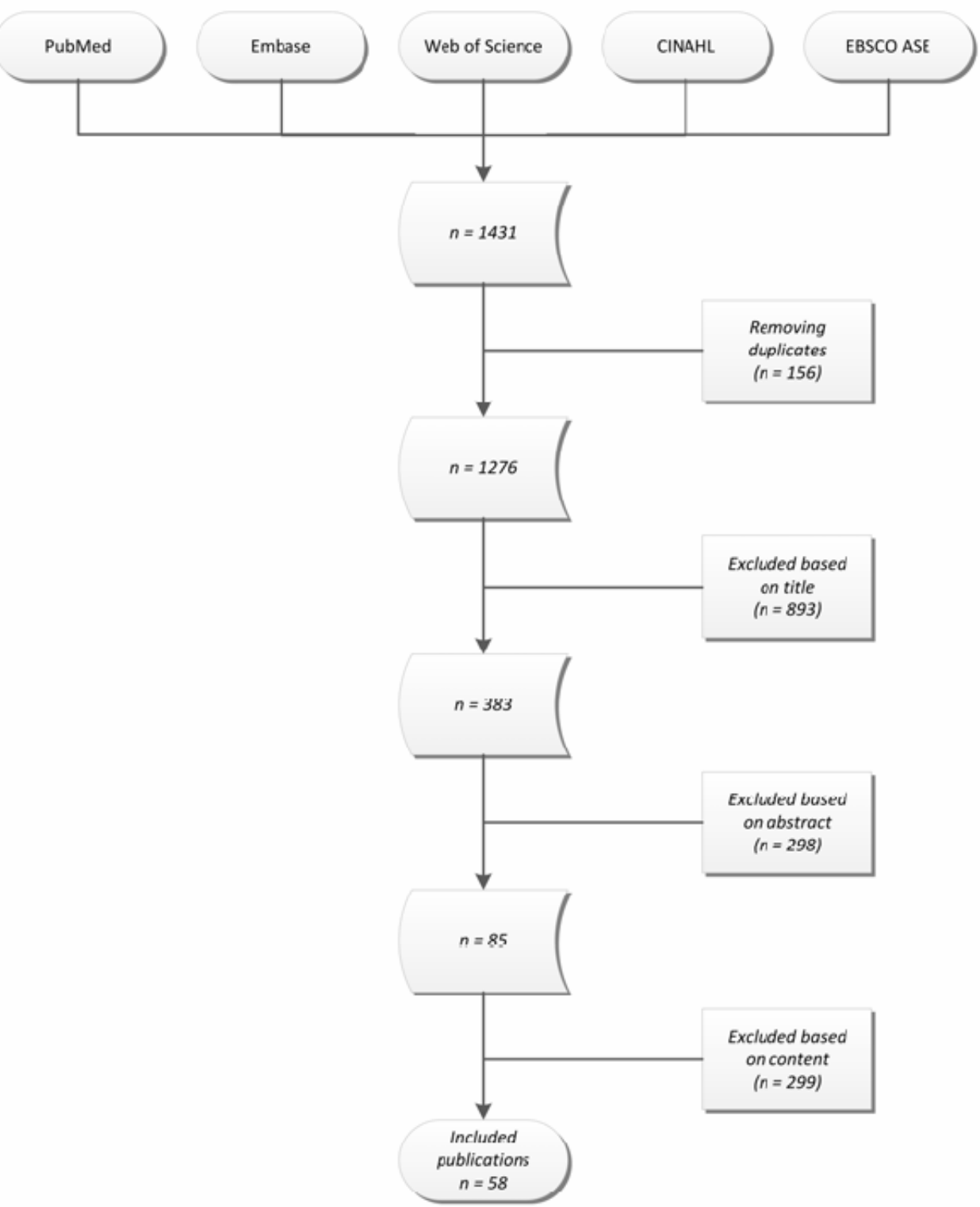


Meulendijks, A., Batenburg, R., Wetering, R. van de. A classification framework for clinical information system implementation in hospitals. International Journal of Organisational Design and Engineering: 2012, 2(4), 402-419

Figure 3 Overview of the number of selected publications by year (see online version for colours)

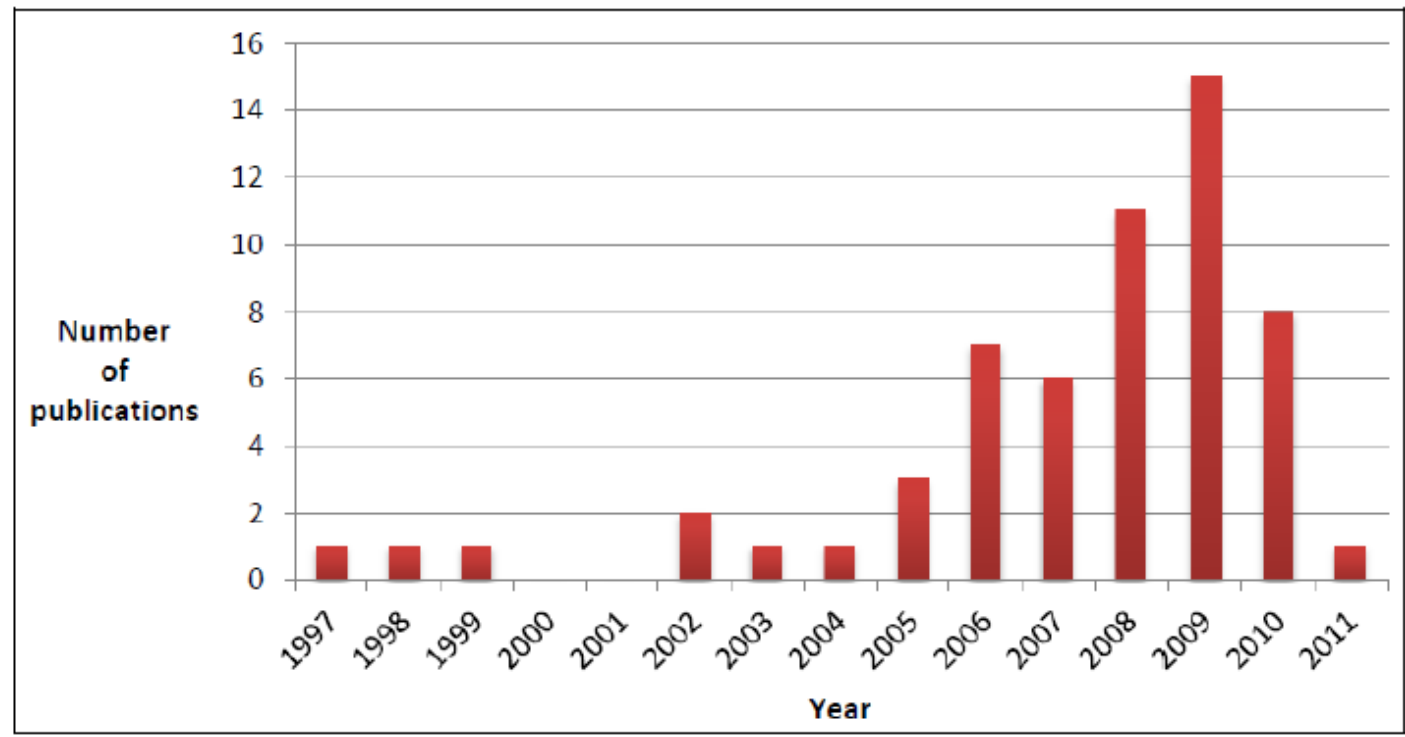

Figure 4 Synthesis of the CSF classifications in seven selected publications, and the mapping of them into weight classification categories

\begin{tabular}{|c|c|c|c|c|c|c|c|}
\hline & $\begin{array}{l}\text { Dlvetweit et al., } \\
\text { (2007) }\end{array}$ & $\begin{array}{l}\text { Stablein et at } \\
\text { (2003) }\end{array}$ & $\begin{array}{l}\text { Kouroubalf } \\
\text { (2003) }\end{array}$ & $\begin{array}{l}\text { Keshavjee et } \\
\text { at. (2006) }\end{array}$ & $\begin{array}{l}\text { Marques et al. } \\
\text { (2011) }\end{array}$ & $\begin{array}{l}\text { Callen et al. } \\
\text { (2009) }\end{array}$ & $\begin{array}{l}\text { Van der Mecijden } \\
\text { et al. (2003) }\end{array}$ \\
\hline System & $\begin{array}{l}\text { - Features of the } \\
\text { EMR system }\end{array}$ & & - Technology & - Technology & $\begin{array}{l}\text { - Technology } \\
\text { context }\end{array}$ & & - System quslity \\
\hline User & & $\begin{array}{l}\text { - Access to } \\
\text { information }\end{array}$ & - Education & -People & $\begin{array}{l}\text { - Humbn } \\
\text { context }\end{array}$ & $\begin{array}{l}\text { - Individusl } \\
\text { context }\end{array}$ & $\begin{array}{l}\text { - Usage } \\
\text { - User } \\
\text { satisfaction } \\
\text { - Individusi } \\
\text { impoct }\end{array}$ \\
\hline $\begin{array}{l}\text { Project } \\
\text { management }\end{array}$ & $\begin{array}{l}\text { - Leadership } \\
\text { - The implemen- } \\
\text { tation process }\end{array}$ & & - Leadership & -Process & & & \\
\hline Resources & - Resources & - Ir composition & & & & & \\
\hline Organization & $\begin{array}{l}\text { - Organizational } \\
\text { culture and } \\
\text { climste }\end{array}$ & $\begin{array}{l}\text { - External environment } \\
\text { - Orgsnizational } \\
\text { lesdership } \\
\text { - Organization structure } \\
\text { and function } \\
\text { - Organizational culture }\end{array}$ & $\begin{array}{l}\text { - Orgonizational } \\
\text { structurez } \\
\text { - The environment }\end{array}$ & & $\begin{array}{l}\text { - Organizational } \\
\text { context } \\
\text { - Environment } \\
\text { context }\end{array}$ & $\begin{array}{l}\text { - Clinical unit } \\
\text { context } \\
\text { - Organizational } \\
\text { context }\end{array}$ & $\begin{array}{l}\text { - Orgsonizational } \\
\text { impsct }\end{array}$ \\
\hline Worknow & & $\begin{array}{l}\text { - Core standordization } \\
\text { - Order management } \\
\text { process }\end{array}$ & & & & & $\begin{array}{l}\text { - Information } \\
\text { quality }\end{array}$ \\
\hline $\begin{array}{l}\text { IT } \\
\text { intrastructure }\end{array}$ & & - Ir infrastructure & & & & & \\
\hline
\end{tabular}


Meulendijks, A., Batenburg, R., Wetering, R. van de. A classification framework for clinical information system implementation in hospitals. International Journal of Organisational Design and Engineering: 2012, 2(4), 402-419

\section{Appendix}

The 58 included publications, by year

\section{1}

1 Nakamura, M.M., Ferris, T.G., Desroches, C.M. and Jha, A.K. (2011) 'Electronic health record adoption by children's hospitals in the United States', Archives of Pediatrics, Vol. 164, No. 12, pp.1145-1151.

2 Pare, G., Sicotte, C., Poba-Nzaou, P. and Balouzakis, G. (2011) 'Clinicians' perceptions of organizational readiness for change in the context of clinical information system projects: insights from two cross-sectional surveys', Implementation Science, IS, Vol. 6, No. 1, 15p.

\section{0}

3 Ayatollahi, H., Bath, P.A. and Goodacre, S. (2010) 'Factors influencing the use of IT in the emergency department: a qualitative study', Health Informatics Journal, Vol. 16, No. 3, pp.189-200.

4 Culler, S.D., Jose, J., Kohler, S. and Rask, K. (2011) 'Nurses perceptions and experiences with the implementation of a medication administration system', Computers Informatics Nursing, Vol. 29, No. 5, pp.280-288.

5 Duyck, P., Pynoo, B., Devolder, P., Voet, T., Adang, L., Ovaere, D. and Vercruysse, J. (2010) 'Monitoring the PACS implementation process in a large university hospital discrepancies between radiologists and physicians', Journal of Digital Imaging : The Official Journal of the Society for Computer Applications in Radiology, Vol. 23, No. 1, pp.73-80.

6 Egleson, N., Kang, J.H., Collymore, D., Esmond, W., Gonzalez, L., Pong, P. and Sherman, L. (2010) 'A health center controlled network's experience in ambulatory care EHR implementation', Journal of Healthcare Information Management: JHIM, Vol. 24, No. 2, 28p.

7 Peute, L.W., Aarts, J., Bakker, P.J.M. and Jaspers, M.W.M. (2010) 'Anatomy of a failure: a sociotechnical evaluation of a laboratory physician order entry system implementation', International Journal of Medical Informatics, Vol. 79, No. 4, pp.58-70.

8 Shield, R.R., Goldman, R.E., Anthony, D.A., Wang, N., Doyle, R.J. and Borkan, J. (2010) 'Gradual electronic health record implementation: new insights on physician and patient adaptation', Annals of Family Medicine, Vol. 8, No. 4, 316p.

9 Skorve, E. (2010) 'Patient safety, resilience and ICT. A reason for concern?', Studies in Health Technology and Informatics, Vol. 157, 199p.

$$
2009
$$

10 Bahensky, J. and Nyarko, K.A. (2009) 'HIT implementation in critical access hospitals: extent of implementation and business strategies supporting IT use', Journal of Medical Systems, Vol. 35, No. 4, pp.599-607.

11 Barakah, D.M. and Alwakeel, S.S. (2009) 'Impact of CPOE on physicians and dentists' work performance at King Saud Medical Complex Hospital: a case study', Proceedings of the World Congress on Engineering and Computer Science, Vol. 1, pp.20-22.

12 Boonstra, A. and Govers, M.J.G. (2009) 'Understanding ERP system implementation in a hospital by analysing stakeholders', New Technology, Work and Employment, Vol. 24, No. 2, pp.177-193.

13 Callen, J., Braithwaite, J. and Westbrook, J. (2009) 'The importance of medical and nursing sub-cultures in the implementation of clinical information systems', Methods of Information in Medicine, Vol. 48, No. 2, pp.196-202. 
Meulendijks, A., Batenburg, R., Wetering, R. van de. A classification framework for clinical information system implementation in hospitals. International Journal of Organisational Design and Engineering: 2012, 2(4), 402-419

The 58 included publications, by year (continued)

2009

14 Carayon, P., Smith, P., Hundt, A.S., Kuruchittham, V. and Li, Q. (2009) 'Implementation of an electronic health records system in a small clinic: the viewpoint of clinic staff', Behaviour \& Information Technology, Vol. 28, No. 1, pp.5-20.

15 Cornford, T., Dean, B., Savage, I., Barber, N. and Jani, Y. (2009) Electronic Prescribing in Hospitals-challenges and Lessons Learned, NHS Connecting for Health [online] http://www.connectingforhealth.nhs.uk/systemsandservices/eprescribing/challenges/Final_re port.pdf (accessed 22 June 2011).

16 Georgiou, A., Ampt, A., Creswick, N., Westbrook, J.I. and Braithwaite, J. (2009) 'Computerized provider order entry - what are health professionals concerned about? A qualitative study in an Australian hospital', International Journal of Medical Informatics, Vol. 78 , No. 1, pp. 60-70.

17 Goroll, A.H., Simon, S.R., Tripathi, M., Ascenzo, C. and Bates, D.W. (2009) 'Community-wide implementation of health information technology: the Massachusetts eHealth collaborative experience', Journal of the American Medical Informatics Association, Vol. 16, No. 1, 132p.

18 Hains, I.M., Fuller, J.M., Ward, R.L. and Pearson, S-A. (2009) 'Standardizing care in medical oncology: are web-based systems the answer?', Cancer, Vol. 115, No. 23 , pp. $5579-88$.

19 Halbesleben, J., Wakefield, D., Ward, M.M., Brokel, J. and Crandall, D. (2009). The relationship between super users' attitudes and employee experiences with clinical information systems', Medical Care Research and Review, Vol. 66, No. 1, 82p.

20 Jensen, T.B., Kjargaard, A. and Svejvig, P. (2009) 'Using institutional theory with sensemaking theory: a case study of information system implementation in healthcare', Journal of Information Technology, Vol. 24, No. 4, pp.343-353.

21 Nanji, K.C., Cina, J., Patel, N., Churchill, W., Gandhi, T.K and Poon, E.G. (2009) 'Overcoming barriers to the implementation of a pharmacy bar code scanning system for medication dispensing: a case study', Journal of the American Medical Informatics Association, JAMIA, Vol. 16, No. 5, pp.645-650.

22 Oroviogoicoechea, C. and Watson, R. (2009) 'A quantitative analysis of the impact of a computerised information system on nurses' clinical practice using a realistic evaluation framework', International Journal of Medical Informatics, Vol. 78, No. 12, pp.839-849.

23 Spetz, J. and Keane, D. (2009) 'Information technology implementation in a rural hospital: a cautionary tale', Journal of Healthcare Management/American College of Healthcare Executives, Vol. 54, No. 5, 337p.

24 Tietze, M.F., Williams, J. and Galimbertti, M. (2009) 'Rural hospital information technology implementation for safety and quality improvement: lessons learned', Computers, Informatics, Nursing: CIN, Vol. 27, No. 4, pp.206-214.

25 Weber, S., Crago, E.A, Sherwood, P.R and Smith, T. (2009) 'Practitioner approaches to the integration of clinical decision support system technology in critical care', The Journal of Nursing Administration, Vol. 39, No. 11, pp.465-469.

26 Wurster, C., Lichtenstein, B. and Hogeboom, T. (2009) 'Strategic, political, and cultural aspects of IT implementation: improving the efficacy of an IT system in a large hospital', Journal of Healthcare Management/American College of Healthcare Executives, Vol. 54, No. 3, 191p. 
Meulendijks, A., Batenburg, R., Wetering, R. van de. A classification framework for clinical information system implementation in hospitals. International Journal of Organisational Design and Engineering: 2012, 2(4), 402-419

The 58 included publications, by year (continued)

2008

27 André, B., Ringdal, G. and Loge, J. (2008) 'The importance of key personnel and active management for successful implementation of computer-based technology in palliative care: results from a qualitative study', Computers, Vol. 26, No. 4, pp.183-189.

28 Bhattacharyya, S.B. (2008) 'Implementation challenges for health care IT in India: a case study', Health Information and Libraries Journal, Vol. 25, No. 3, pp.225-228.

29 Bahensky, J.A., Moreau, B., Frieden, R. and Ward, M.M. (2008) 'Critical access hospital informatics: how two rural Iowa hospitals overcame challenges to achieve IT excellence', Journal of Healthcare Information Management: JHIM, Vol. 22, No. 2, pp.16-22.

30 Culler, S.D., Jose, J., Kohler, S., Edwards, P., Dee, A.D., Sainfort, F. and Rask, K (2008) 'Implementing a pharmacy system: facilitators and barriers', Journal of Medical Systems, Vol. 33 , No. 2, pp.81-90.

31 Egger Halbeis, C.B., Epstein, R.H., Macario, A., Pearl, R.G. and Grunwald, Z. (2008) 'Adoption of anesthesia information management systems by academic departments in the United States', Anesthesia \& Analgesia, Vol. 107, No. 4, 1323p.

32 Kraus, S., Barber, T., Briggs, B. and Kall, G. (2008) 'Implementing computerized physician order management at a community hospital', Joumal on Quality, Vol. 34, No. 2, pp.74-84

33 Menachemi, N., Brooks, R.G., Schwalenstocker, E. and Simpson, L. (2008) 'Use of health information technology by children's hospitals in the United States', Pediatrics, Vol. 123, Suppl., pp.S80-S84.

34 Rankin, S.B. and White, B.a. (2008) 'Healthcare IT and Connecticut's acute-care hospitals. An analysis of trends, barriers, impacts and perspectives', Journal of Healthcare Information Management: JHIM, Vol. 22, No. 3, pp.57-63.

35 Zandieh, S.O., Yoon-flannery, K, Kuperman, G.J., Langsam, D.J., Hyman, D. and Kaushal, R. (2008) 'Challenges to EHR implementation in electronic- versus paper-based office practices', Joumal of General Internal Medicine, Vol. 23, No. 6, pp.755-761.

$$
2007
$$

36 Hendy, J., Fulop, N., Reeves, B.C., Hutchings, A. and Collin, S. (2007) 'Implementing the NHS information technology programme: qualitative study of progress in acute trusts', $B M J$, (Clinical research ed.), Vol. 334, No. 7608, 1360p.

37 Jensen, T.B. and Aanestad, M. (2007) 'Hospitality and hostility in hospitals: a case study of an EPR adoption among surgeons', European Journal of Information Systems, Vol. 16, No. 6, pp.672-680.

38 Lee, T-T. (2007) 'Nurses' experiences using a nursing information system: early stage of technology implementation', Computers, Informatics, Nursing: CIN, Vol. 25, No. 5 , pp.294-300.

39 Nitrosi, A., Borasi, G., Nicoli, F., Modigliani, G., Botti, A., Bertolini, M. and Notari, P. (2007) 'A filmless radiology department in a full digital regional hospital: quantitative evaluation of the increased quality and efficiency', Journal of Digital Imaging: The Official Journal of the Society for Computer Applications in Radiology, Vol. 20, No. 2, pp.140-148.

40 Øvretveit, J., Scott, T., Rundall, T.G., Shortell, S.M. and Brommels, M. (2007) 'Improving quality through effective implementation of information technology in healthcare', International Journal for Quality in Health Care: Journal of the International Society for Quality in Health Care/ISQua, Vol. 19, No. 5, pp.259-266. 
Meulendijks, A., Batenburg, R., Wetering, R. van de. A classification framework for clinical information system implementation in hospitals. International Journal of Organisational Design and Engineering: 2012, 2(4), 402-419

The 58 included publications, by year (continued)

\begin{tabular}{|c|c|}
\hline \multicolumn{2}{|r|}{2006} \\
\hline 41 & $\begin{array}{l}\text { Ammenwerth, E., Iller, C. and Mahler, C. (2006) 'IT-adoption and the interaction of task, } \\
\text { technology and individuals: a fit framework and a case study', BMC Medical Informatics } \\
\text { and Decision Making, Vol. } 6 \text {, No. } 3 \text {. }\end{array}$ \\
\hline 42 & $\begin{array}{l}\text { Barron, W., Reed, R. and Forsythe, S. (2006) 'Implementing computerized provider order } \\
\text { entry with an existing clinical information system', Journal on Quality, Vol. } 32 \text {, No. 9, } \\
\text { pp.506-516. }\end{array}$ \\
\hline 43 & $\begin{array}{l}\text { Bomba, D. and Land, T. (2006) 'The feasibility of implementing an electronic prescribing } \\
\text { decision support system: a case study of an Australian public hospital', Australian Health } \\
\text { Review: A Publication of the Australian Hospital Association, Vol. 30, No. 3, pp.380-388. }\end{array}$ \\
\hline 44 & $\begin{array}{l}\text { Desai, A., Desai, P., Blum, M. and Bates, D. (2006) 'Leveraging change: educational } \\
\text { opportunities in information technology implementation', Journal of Clinical Outcomes } \\
\text { Management, Vol. } 13, \text { No. } 7,372 \mathrm{p} \text {. }\end{array}$ \\
\hline 45 & $\begin{array}{l}\text { Lapointe, L. and Rivard, S. (2006) 'Getting physicians to accept new information } \\
\text { technology: insights from case studies', Canadian Medical Association Journal, Vol. 174, } \\
\text { No. } 11,1573 \text { p. }\end{array}$ \\
\hline 46 & $\begin{array}{l}\text { Marang-van de Mheen, P.J., Stadlander, M.C. and Kievit, J. (2006) 'Adverse outcomes in } \\
\text { surgical patients: implementation of a nationwide reporting system', Quality \& Safety in } \\
\text { Health Care, Vol. } 15 \text {, No. 5, pp.320-324. }\end{array}$ \\
\hline 47 & $\begin{array}{l}\text { McAlearney, A.S., Chisolm, D.J., Schweikhart, S., Medow, M.A. and Kelleher, K (2006) } \\
\text { 'The story behind the story: physician skepticism about relying on clinical information } \\
\text { technologies to reduce medical errors', International Journal of Medical Informatics, } \\
\text { Vol. 76, Nos. 11-12, pp.836-842. }\end{array}$ \\
\hline 48 & $\begin{array}{l}\text { Popernack, M.L. (2006) 'A critical change in a day in the life of intensive care nurses: rising } \\
\text { to the e-challenge of an integrated clinical information system', Critical Care Nursing } \\
\text { Quarterly, Vol. } 29 \text {, No. } 4 \text {, pp.362-375. }\end{array}$ \\
\hline & 2005 \\
\hline
\end{tabular}

49 Bayley, K., Savitz, L., Rodriguez, G., Gillanders, W. and Stoner, S. (2005) 'Barriers associated with medication information handoffs', in Henriksen, K., Battles, J., Marks, E. and Lewin, D. (Eds.): Advances in Patient Safety: From Research to Implementation: Concepts and Methodology, pp.87-102, Agency for Healthcare, Rockville, MD.

50 Menachemi, N., Burke, D., Clawson, A. and Brooks, R G. (2005) 'Information technologies in Florida's rural hospitals: does system affiliation matter?', The Journal of Rural Health, Vol. 21, No. 3, pp.263-268.

51 Miller, A.A. and Phillips, A.K. (2005) 'A contemporary case study illustrating the integration of health information technologies into the organisation and clinical practice of radiation oncology', The HIM Journal, Vol. 34, No. 4, 136p.

$$
2004
$$

52 Doolin, B. (2004) 'Power and resistance in the implementation of a medical management information system', Information. Systems Journal, Vol. 14, No. 4, pp.343-362.

$$
2003
$$

53 Ash, J.S., Gorman, P.N., Lavelle, M., Payne, T.H., Massaro, T.A., Frantz, G.L. and Lyman, J.A. (2003) 'A cross-site qualitative study of physician order entry', Journal of the American Medical Informatics Association, Vol. 10, No. 2, 188p.

54 Jones, M. (2003) 'Computers can land people on Mars, why can't they get them to work in a hospital', Methods Inf. Med., Vol. 42, No. 4, pp.410-415. 
Meulendijks, A., Batenburg, R., Wetering, R. van de. A classification framework for clinical information system implementation in hospitals. International Journal of Organisational Design and Engineering: 2012, 2(4), 402-419

The 58 included publications, by year (continued) 2002

55 Barr, B.J. (2002) 'Managing change during an information systems transition', $A O R N$ Journal, Vol. 75 , No. 6, pp.1085-1092.

1999

56 Sobol, M., Alverson, M. and Lei, D. (1999) 'Barriers to the adoption of computerized technology in health care systems', Topics in Health Information Management, Vol. 19, No. $4,1 \mathrm{p}$.

\section{8}

57 Sicotte, C., Denis, J.L. and Lehoux, P. (1998) 'The computer based patient record: a strategic issue in process innovation', Journal of Medical Systems, Vol. 22, No. 6 , pp.431-443.

1997

58 Paré, G., Elam, J.J. and Ward, C.G. (1997) 'Implementation of a patient charting system: challenges encountered and tactics adopted in a burn center', Journal of Medical Systems, Vol. 21 , No. 1, pp.49-66. 